\title{
Experimental Endotoxemia Induces Leukocyte Adherence and Plasma Extravasation Within the Rat Pial Microcirculation
}

\author{
J. ZHOU ${ }^{1,2}$, M. SCHMIDT ${ }^{1,5,6,7}$, B. JOHNSTON ${ }^{2,3,4}$, F. WILFART ${ }^{1,7}$, S. WHYNOT $^{1}$,

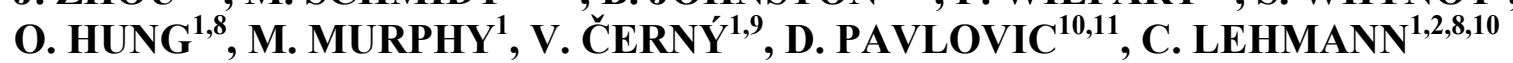 \\ ${ }^{1}$ Departments of Anesthesia, ${ }^{2}$ Microbiology and Immunology, ${ }^{3}$ Pediatrics, ${ }^{4}$ Pathology, ${ }^{5}$ Physiology, \\ ${ }^{6}$ Neurosurgery, ${ }^{7}$ Biomedical Engineering, ${ }^{8}$ Pharmacology, Dalhousie University, Halifax, NS, \\ Canada, ${ }^{9}$ Department of Anesthesiology and Intensive Care Medicine, Charles University Prague, \\ Faculty of Medicine Hradec Králové, University Hospital Hradec Králové, Czech Republic, \\ ${ }^{10}$ Department of Anesthesiology and Intensive Care Medicine, Ernst Moritz Arndt University \\ Greifswald, Germany, ${ }^{11}$ Department of Pathophysiology, American School of Medicine, European \\ University, Belgrade, Serbia
}

Received July 16, 2010

Accepted May 3, 2011

On-line October 12, 2011

\section{Summary}

Disturbance of capillary perfusions due to leukocyte adhesion, disseminated intravascular coagulation, tissue edema is critical components in the pathophysiology of sepsis. Alterations in brain microcirculation during sepsis are not clearly understood. The aim of this study is to gain an improved understanding of alterations through direct visualization of brain microcirculations in an experimental endotoxemia using intravital microscopy (IVM). Endotoxemia was induced in Lewis rats with Lipopolysaccharide (LPS, $15 \mathrm{mg} / \mathrm{kg}$ i.v.). The dura mater was removed via a cranial window to expose the pial vessels on the brain surface. Using fluorescence dyes, plasma extravasation of pial venous vessels and leukocyte-endothelial interaction were visualized by intravital microscopy $4 \mathrm{~h}$ after LPS administration. Plasma cytokine levels of IL1- $\beta$, IL- 6 , IFN- $\gamma$, TNF- $\alpha$ and KC/GRO were evaluated after IVM. A significant plasma extravasation of the pial venous vessels was found in endotoxemia rats compared to control animals. In addition, a significantly increased number of leukocytes adherent to the pial venous endothelium was observed in septic animals. Endotoxemia also induced a significant elevation of plasma cytokine levels of IL1- $\beta$, IL-6, IFN- $\gamma$, TNF- $\alpha$ and KC/GRO. Endotoxemia increased permeability in the brain pial vessels accompanied by an increase of leukocyte-endothelium interactions and an increase of inflammatory cytokines in the plasma.

\section{Key words}

Sepsis • Endotoxin • Intravital microscopy • Blood brain barrier

\section{Corresponding author}

C. Lehmann, Department of Anesthesia, 6H Tupper Building, 5850 College Street, Halifax, NS, B3H 1X5, Canada. E-mail: chlehmann@dal.ca

\section{Introduction}

Sepsis is the leading cause of death in intensive care units resulting from a systemic inflammatory response to infection. In response to pathogen associated molecular patterns (PAMPs), large quantities of proinflammatory cytokines are released into the circulation and initiate an unregulated immune cascade that can cause multiple organ failure (Streck et al. 2008, Wang et al. 2008). Alterations in the microcirculation have been suggested to play a critical role in pathophysiology of sepsis (Lundy et al. 2009).

One of the first organs affected in sepsis is the brain. The brain has an immunologic advantage due to its anatomical separation from the immune system by the blood brain barrier (BBB), a lack of lymphatic drainage system, and low expression of histocompatibility complex antigens. The BBB plays an important role in controlling the entry of inflammatory cells and macromolecules into the brain via the selective permeability of microvascular endothelial cell tight junctions and associated astrocytes (Pytel et al. 2009). 
Although the mechanism is not clear, disruption of the BBB and the resulting brain edema has been proposed as a major factor for the pathophysiology of septic encephalopathy and subsequent sepsis induced brain dysfunction. Conflicting evidence exists showing both increased permeability of the BBB in septic encephalopathy (Mayhan 1998, Siami et al. 2008) and unchanged BBB permeability with intact tight junctions of endothelial cell in endotoxemic animals (Bickel et al. 1998, Rosengarten et al. 2008).

To investigate the effect of endotoxin on permeability of the BBB, we used intravital fluorescence microscopy and fluorescence dyes to directly visualize the interaction of leucocytes and endothelium and variation in permeability of the $\mathrm{BBB}$ in an in vivo endotoxemia rat model.

\section{Material and Methods}

\section{Animals}

Male Lewis rats (weight 250-300 g) were purchased from Charles River (Wilmington, MA, USA) and maintained in the animal care facility of the Faculty of Medicine at Dalhousie University. Animals were provided with water and rodent chow ad libitum under standard 12-hour light/dark rhythmic conditions. All animal experimentations were undertaken in compliance with the guidelines of the Canadian Council on Animal Care.

\section{Anesthesia and preparation}

Rats were anesthetized with an initial intraperitoneal (i.p.) injection of sodium pentobarbital (65 mg/kg, Ceva Sante Animale, Montrol, QC, Canada) and maintained by repeated intravenous (i.v.) injections of pentobarbital $(15 \mathrm{mg} / \mathrm{kg})$. The head and right groin regions were shaved. To maintain stable body temperature, rats were placed in the dorsal position on a heating pad. Core body temperature was monitored through a rectal probe. An oxygen tube was connected to the mouth for additional oxygen supply. An incision was made in the skin of the right groin exposing both the femoral artery and vein. After insertion of a $22 \mathrm{G} 1^{\prime \prime}$ JELCO ${ }^{\circledR}$ I.V. Catheter into the femoral artery arterial blood pressure, heart rate and pulse oximetry were continuously monitored via a Datex Engstrom monitor (Salo, Finland). A second 22G 1" JELCO ${ }^{\circledR}$ I.V. Catheter then inserted into the femoral artery for a continuous infusion of $0.9 \%$ sodium chloride (Montreal, QC,
Canada) at a rate of $1 \mathrm{ml} / \mathrm{h}$.

Animals were randomly assigned to experimental (septic) or control groups. In the experimental group, lipopolysaccharide (LPS, from Escherichia coli, serotype O26:B6, Sigma-Aldrich, Oakville, ON, Canada) was given i.v at $15 \mathrm{mg} / \mathrm{kg}$. Control animals were given an equal volume of normal saline.

\section{Cranial window surgery}

After stabilization in a stereotactic frame, a midline incision of the scalp was made. The underlying soft tissue was removed and bleeding was stopped. Using a low speed drill, a cranial window (approximately $3 \times 3 \mathrm{~mm}$ ) was made right of the middle sagittal line between the bregma and lambdoid sutures. Constant irrigation with an artificial cerebrospinal fluid was used during drilling to avoid brain overheating. Then, dura mater was removed using micro-iris scissors (Codman Shurtleff Inc., Raynham, MA, USA) and the cerebral surface was covered with artificial cerebrospinal fluid.

\section{Fluorescence intravital microscopy (IVM)}

Four hours after injection of LPS or normal saline, rats were injected $5 \%$ fluorescein isothiocyanate (FITC)-albumin (Sigma-Aldrich, ON, Canada) solution (i.v.; $50 \mathrm{mg} / \mathrm{kg}$ ) and $0.05 \%$ Rhodamine $6 \mathrm{G}$ (SigmaAldrich) solution (i.v.; $0.75 \mathrm{mg} / \mathrm{kg}$ ). Intravital microscopy was performed with an upright fluorescence microscope (DM5000B, Leica, Richmond Hill, ON, Canada) equipped with a mercury bulb (Short ARC, HBO, 100W, Osram, Germany), an external light source (Leica CTR 5000), eGFP blue and N21 green filters, objectives (NPLAN L 20x/0.4, HC PLAN 10x/22 n) and a digital highspeed camera (EM-CCD, C9100, Hamamatsu, Japan). Images were captured using Volocity 5.0 software (PerkinElmer, Woodbridge, ON, Canada).

Five small pial venous vessels (diameter $<100 \mu \mathrm{m})$ with clear focus were randomly selected in each animal for $30 \mathrm{~s}$ video recording of leukocyteendothelium interaction and $3 \mathrm{~s}$ recording for plasma extravasation. The sensitivity of brightness was adjusted for appropriate exposure to capture the complete range of brightness. Images were recorded with a final magnification of 200x.

\section{Plasma cytokine multiplex assay}

Arterial blood samples were collected at the end of experiments using heparinized syringes. Animals 
were sacrificed by overdose of pentobarbital $(100 \mathrm{mg} / \mathrm{kg}$ i.v.). Plasma was separated by centrifugation and stored at $-80{ }^{\circ} \mathrm{C}$ for later cytokine analysis. Plasma cytokine levels were examined using a Meso Scale Discovery multiplex spot assay for rat interleukin 1 beta (IL1- $\beta$ ), interleukin 6 (IL-6), tumor necrosis factor- $\alpha$ (TNF- $\alpha$ ), interferon $\gamma$ (IFN- $\gamma$ ), and growth-related oncogene (KC/GRO, MSD, Gaithersburg, MD). Samples were measured using a MSD SECTOR Imager 2400 and analyzed with MSD Discovery Workbench software.

\section{Data analysis}

A well focused frame of the video clip was selected and exported as uncompressed TIFF-image with 1000x1000 pixels resolution ( 8 bit gray scale) from Volocity to Image $\mathrm{J}$ (National Institutes of Health, Bethesda, MD). To evaluate plasma extravasation, we measured the intensity of FITC fluorescence outside and inside venous vessels from each image and calculated the ratio of pixel intensity. Only the focused regions of the image were selected for this measurement.

To evaluate leukocyte-endothelium interactions, a $100 \times 100$ pixel $(64 \mu \mathrm{m} \times 64 \mu \mathrm{m})$ grid was applied to the exported pictures. Using the video clip from the still images captured and noted above, the number of leukocytes firmly adherent to the vessels for $30 \mathrm{~s}$ in the focused squares was counted as adhesion leukocytes or stickers and the mean density of leukocytes per square was determined. The evaluation of plasma extravasation and leukocyte-endothelium interaction was performed in a blinded fashion.

\section{Statistical analysis}

All data were analyzed with Sigma Stat/Plot (Systat Software Inc., San Jose, CA). Normal distribution of data was tested using the KolmogorovSmirnov test. T-tests and Mann-Whitney-Rank-SumTests (MWRS) were performed for parametric and nonparametric data analysis, respectively. All normally distributed data are presented as mean \pm standard deviation. Non-normally distributed data are presented as median in Box-Plots, in which the boxes described the $25-75 \%$ percentile and whiskers the 10-90\% percentile. Mean arterial pressure and heart rate were analyzed by a two-way analysis of variance (repeated measures in the factor of time), followed by the Bonferroni test. Probability values less than 0.05 were considered significant.
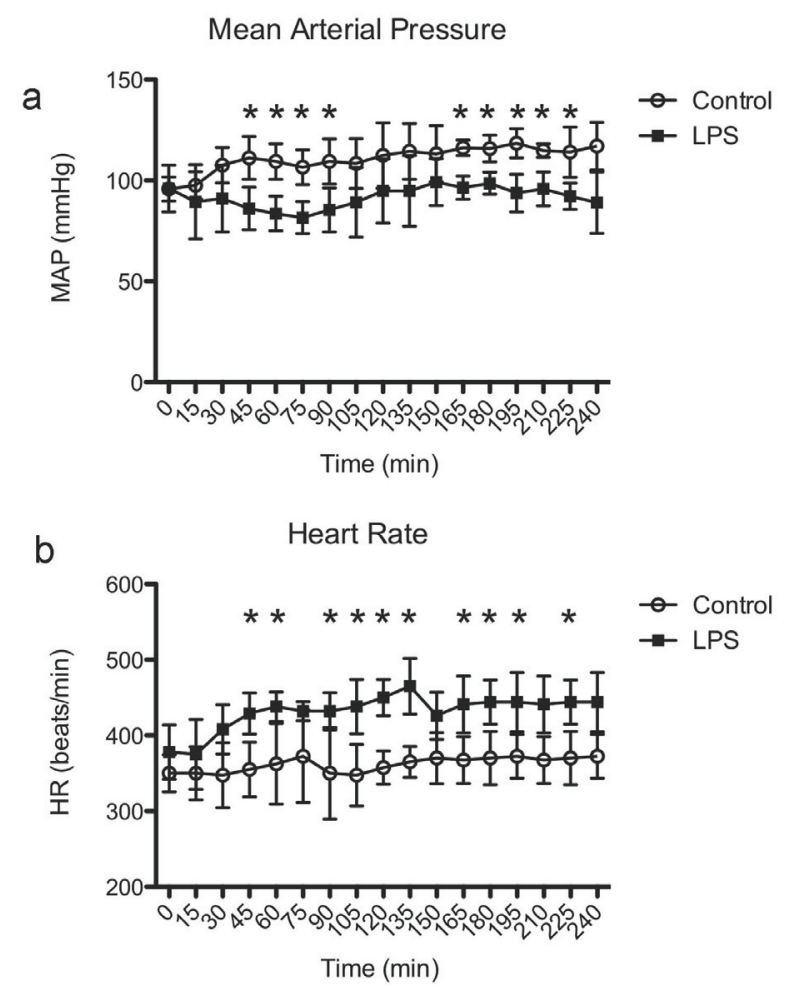

Fig. 1. a) Arterial blood pressure (MAP) and b) heart rate (HR) in control and endotoxemic (LPS) animals at the time 0 (from beginning of injection of LPS or normal saline) and every $15 \mathrm{~min}$ interval during experimentation. * indicates a significant difference between the two groups ( $t$-test, $p<0.05$ ).

\section{Results}

Systemic hemodynamic changes

All animals survived surgery and IVM examinations without protocol violations and missing data points. MAP remained stable in control animals (Fig. 1a). Administration of LPS reduced MAP to the levels below than control animals and reached statistically significance $(\mathrm{p}<0.05)$ at $60 \mathrm{~min}$. However, none of the animals reached a MAP lower than $65 \mathrm{~mm} \mathrm{Hg}$. Consistent with reduced MAP, the heart rate in LPS challenged rats was higher than that in controls (Fig. 1b). Body temperature measured by rectal probe remained at normal levels $\left(37.2 \pm 0.6{ }^{\circ} \mathrm{C}\right)$ in both control and LPS challenged rats throughout the experiment.

\section{Permeability of blood brain barrier}

Using intravital fluorescence microscopy, permeability of the blood brain barrier (BBB) was investigated by measuring FITC labeled albumin leakage from small pial vessels (diameters $<100 \mu \mathrm{m}$ ). Control animals shown in Figure 2, demonstrated that FITC labeled albumin remained mainly inside vessel walls 


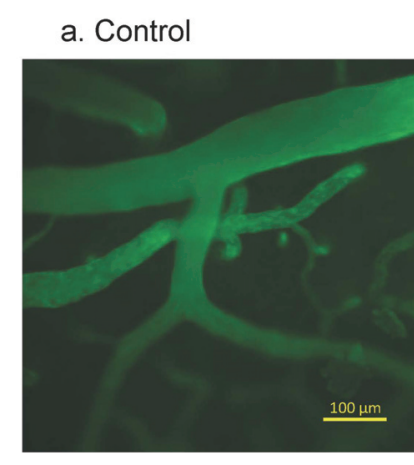

b. Endotoxemia

Fig. 2. Images of pial vessels and surrounding tissues on the control (a) and endotoxemic (b) rat brain 4 hours after saline or LPS administration.

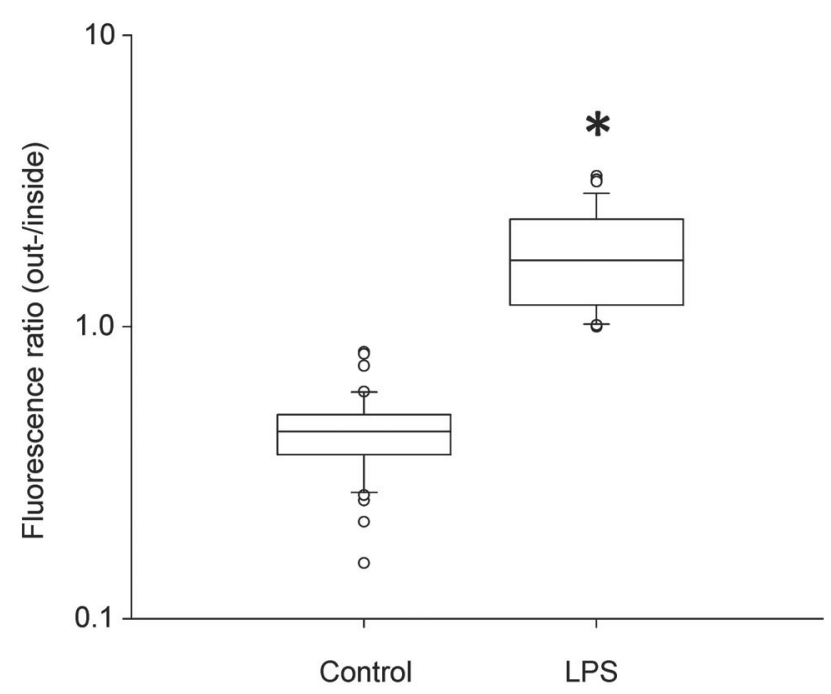

Fig. 3. Vascular permeability in pial microvasculature of control and endotoxemic rats. Ratio of FITC-albumin pixel intensity within vasculature and outside the vasculature was examined in no LPS (Control) and endotoxemic (LPS) rat brains. * indicates a significant difference between the two groups (Mann-Whitney, $\mathrm{P}<0.001) . \mathrm{n}=14$.

(Fig. 2a). Conversely, endotoxemic animals showed a significant amount of FITC-albumin present outside the vessels (Fig. 2b), indicating an extravasation of FITCalbumin from the vessels. To quantify the extravasation, the ratio of the fluorescent intensity outside versus inside vessels quantified. As shown in Figure 3, a significant $(p<0.001)$ increase in fluorescence ratio was observed in LPS challenged groups comparing to the control group.

\section{Leukocyte adherence}

To investigate leukocyte - endothelium interaction, the number of leukocytes firmly adherent to the small vessels (diameter $<100 \mu \mathrm{m}$ ) was evaluated. As shown in Figure 4, LPS challenge significantly increased $(p=0.025)$ the number of leukocytes adherent to the vessel wall.

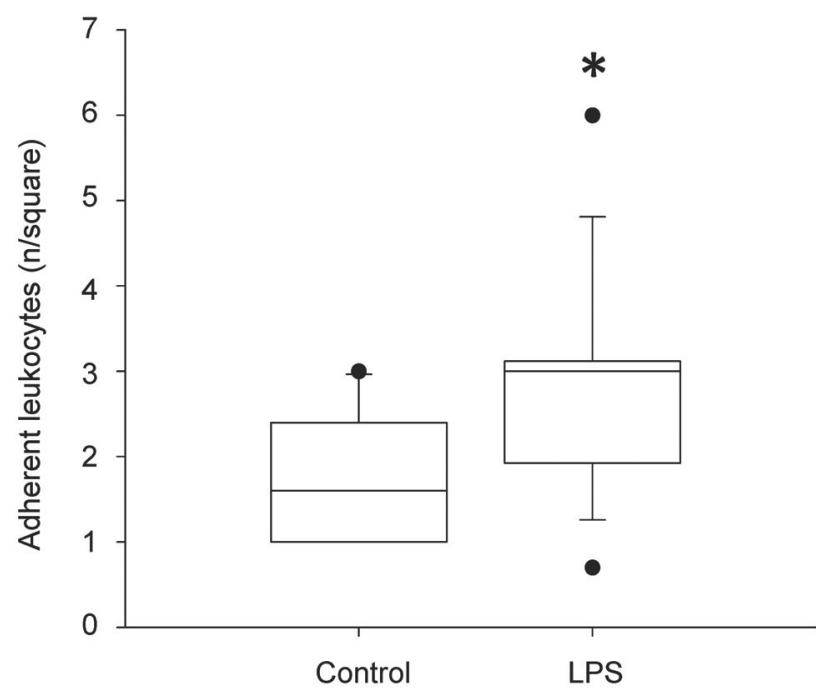

Fig. 4. Number of adherent leukocytes in the pial microvasculature of control and endotoxemic (LPS) rats. The number of adherent rhodamine $6 \mathrm{G}$ labelled leukocytes was determined per square $(64 \mu \mathrm{m} \times 64 \mu \mathrm{m})$ in the focused venous pial vessels. * indicates a significant difference between the two groups (Mann-Whitney, $\mathrm{p}=0.025$ ). Boxplot with median and $25 \% / 75 \%$ percentile. $n=14$.

\section{Plasma cytokines}

Five hours after administration of normal saline or LPS challenge, cytokine levels of IFN- $\gamma$, IL-1, IL-6, $\mathrm{TNF}-\alpha$ and $\mathrm{KC} / \mathrm{GRO}$ in the plasma were significantly (IL- $1 \mathrm{p}<0.05$, TNF- $\alpha$ and KC/GRO $\mathrm{p}<0.01$, IFN- $\gamma$ and IL-6 $\mathrm{p}<0.0001)$ increased in the LPS challenged animals compared to control animals (Fig. 5).

\section{Discussion}

Sepsis induced brain dysfunction, septic encephalopathy, is an early clinical symptom in septic patients. Although its pathophysiology is not well understood and controversies exist, it has been suggested that microcirculation is a key organ in septic pathophysiology and plays a critical role in sepsis development (Siami et al. 2008). In this study, using a well-established endotoxemia rat model and intravital microscopy, we demonstrated that endotoxemia induced an increase in permeability of the brain pial vessels and that this change was accompanied by an increase of leukocyte-endothelial cell interaction.

Lipopolysaccharide (LPS) is an endotoxin from the outer membrane of gram negative bacteria. It is also one of the most potent microbial mediators implicated in the pathogenesis of sepsis. It has been demonstrated that LPS triggers proinflammatory cytokine production, including TNF- $\alpha$ and IL-1 $\beta$, and also upregulates expression of their receptor (Tsao et al. 2001, Alexander 

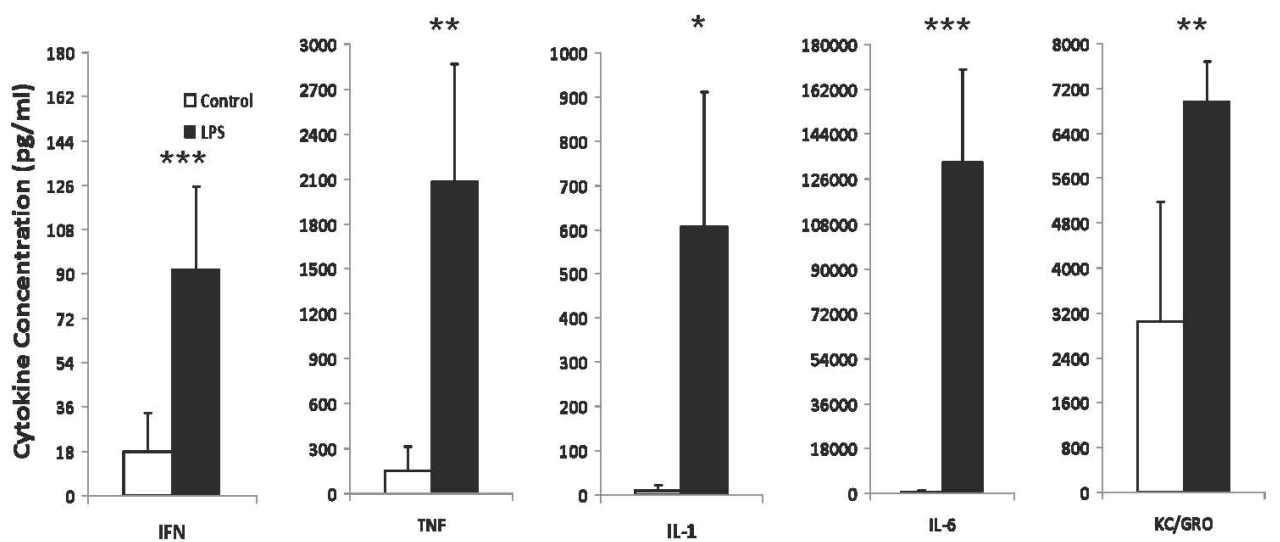

Fig. 5. Plasma cytokine concentration in control and endotoxemic rats (LPS). IL$1 \beta$ : interleukin 1 beta, IL-6: interleukin 6, TNF-a: tumor necrosis factor- $a$, IFN- $\gamma$ : interferon $\gamma$ and $\mathrm{KC} / \mathrm{GRO}$ : growth-related oncogene. * indicates a significant difference between the two groups (t-test, $* \mathrm{p}<0.05$, $* * \mathrm{P}<0.01, \quad * * * \mathrm{p}<0.0001)$. $\mathrm{n}=14$.

et al. 2008). TNF- $\alpha$ acts through its receptor, TNFR1, to induce expression of cell adhesion molecules on endothelial cells (Tsao et al. 2001, Alexander et al. 2008). The cross-linking of adhesion molecules triggers cytoskeletal remodeling in endothelial cells, which allow leukocyte transendothelial migration to proceed (Gaber et al. 2004, Hang et al. 2004). TNF- $\alpha$ also causes increased permeability of the BBB and anti-TNF- $\alpha$ reduces the BBB permeability induced by sepsis (Tsao et al. 2001, Hang et al. 2004). In our experiments, systemic LPS administration induced high levels of the proinflammatory cytokines IL-6, TNF- $\alpha$ and IL- $1 \beta$ in blood circulation. Such a large amount of proinflammatory cytokines may contribute to the increased leukocyteendothelium interaction and promote permeability of the $\mathrm{BBB}$ in endotoxemic rat brains.

LPS may also directly disrupt the BBB thereby increasing permeability in experimental models (Mayhan 1998, Xaio et al. 2001, Gaillard et al. 2003, Osuchowski et al. 2005, Veszelka et al. 2007). It has been demonstrated that injection of LPS transiently disrupted the BBB and allowed ${ }^{14} \mathrm{C}$-sucrose (340Da) but not ${ }^{14} \mathrm{C}$ dextran $(50-100 \mathrm{kDa})$ to cross-tight junctions (Singh et al. 2004, 2007, Osuchowski et al. 2005). In addition, extravasation of insulin and albumin was demonstrated in other septic brains (Xaio et al. 2001, Hofer et al. 2008). However, other studies reported that LPS did not acutely disrupt the BBB in rats (Bickel et al. 1998, Rosengarten et al. 2008). In addition, LPS reduced the permeability of the BBB was reported in other animal models (Kaya et al. 2004, Ahishali et al. 2005). These conflicting results may be due to different serotypes of LPS, different application procedures and dosage, and different tracers used in various animal models.

In our laboratory, we have developed and demonstrated impaired microcirculation of intestine
(Lehmann et al. 2006, 2007) and mesentery (Lehmann et al. 2004, Birnbaum et al. 2006) in endotoxemic rats. Using the same model, we demonstrated significant extravasation of labeled albumin in the pial vessels of endotoxemic rats, suggesting that endotoxin induces opening of the blood brain barrier. Our results are consistent with previous results that found LPS increases permeability of the BBB (Xaio et al. 2001, Hofer et al. 2008).

IL-6 is a multifunctional cytokine with diverse actions. Increased IL-6 production is often associated with sepsis and disruption of the BBB in septic brains (Kabir et al. 2003, Paul et al. 2003). Conversely, IL-6 also acts as an anti-inflammatory cytokine to reduce the migration of leukocytes across the $\mathrm{BBB}$ in mouse bacterial meningitis (Paul et al. 2003). In our experiments, increased plasma levels of IL-6 following LPS treatment correlated with increased permeability of the $\mathrm{BBB}$ and increased leukocyte-endothelium interactions.

Adhesion of leukocytes in post-capillary venules is an early inflammatory response induced in different tissues by a variety of stimuli. LPS induced recruitment of leukocytes adherent to small venules has been reported in several experimental models (Lehmann et al. 2001, 2006). Stimulation by LPS or TNF- $\alpha$ up regulates adhesion molecules on endothelial cells resulting in increased leukocyte interactions with the endothelium (Alexander et al. 2008). In addition, low blood pressure with low shear rates also contributes to increased leukocyte adhesion (Russell et al. 2003). In our experiments, increased number of adherent leukocytes was observed as the result of LPS stimulation. However, it is not clear whether decreased blood pressures in all the endotoxemic rats are significant enough to reduce the shear rates and contribute to increased leukocyte- 
endothelium interaction.

Systemic hypotension and hypoxia may contribute to disruption of the BBB, therefore, MAP, HR and $\mathrm{O}_{2}$ saturation were closely and continuously monitored. Rapid administration of LPS induced a transient drop in MAP. Using a slower rate of LPS administration (about $0.1 \mathrm{ml} / \mathrm{min}$ ) none of the rats exhibited a MAP lower than $65 \mathrm{~mm} \mathrm{Hg}$, the minimal level required to maintain the integrity of the BBB (Ahishali et al. 2005). In addition, all animals were supplied with oxygen so oxygen saturation did not drop below $97 \%$. Other factors which may damage the BBB, such as local mechanical or chemical stimulation, potential excitatory light and temperature of artificial cerebrospinal fluid were controlled in both control and endotoxemic animals. These data suggest that increased permeability of the BBB in LPS challenged rats was not due to the drop of MAP or lack of oxygen, but due to direct immune response to endotoxemia.

Many factors may influence these complex animal experiments. Careful consideration must be given and steps taken to avoid situations, described above, that results in transient drops in MAP, fluid balance during endotoxemia experiments and minor injury/bleeding during cranial window preparation.

In conclusion, using florescence intravital microscopy, we were able to directly examine the cerebral microcirculation through a cranial window. We also demonstrated that endotoxin induced permeability changes in the brain pial vessels and that these changes were accompanied by an increase in leukocyteendothelial cell interactions. This animal model can be used to study mechanisms of sepsis in the brain and effects of therapeutic strategies at the microcirculation levels.

\section{Conflict of Interest}

There is no conflict of interest.

\section{Acknowledgements}

Supported in part by Research project MZO 00179906 from the University Hospital Hradec Králové, Czech Republic.

\section{References}

AHISHALI B, KAYA M, KALAYCI R, UZUN H, BILGIC B, ARICAN N, ELMAS I, AYDIN S, KUCUK M: Effects of lipopolysaccharide on the blood-brain barrier permeability in prolonged nitric oxide blockade-induced hypertensive rats. Int $J$ Neurosci 115: 151-168, 2005.

ALEXANDER JJ, JACOB A, CUNNINGHAM P, HENSLEY L, QUIGG RJ: TNF is a key mediator of septic encephalopathy acting through its receptor, TNF receptor-1. Neurochem Int 52: 447-456, 2008.

BICKEL U, GRAVE B, KANG YS, DEL REY A, VOIGT K: No increase in blood-brain barrier permeability after intraperitoneal injection of endotoxin in the rat. J Neuroimmunol 85: 131-136, 1998.

BIRNBAUM J, HEIN OV, LUHRS C, RUCKBEIL O, SPIES C, ZIEMER S, GRUNDLING M, USICHENKO T, MEISSNER K, PAVLOVIC D, KOX WJ, LEHMANN C: Effects of coagulation factor XIII on intestinal functional capillary density, leukocyte adherence and mesenteric plasma extravasation in experimental endotoxemia. Crit Care 10: R29, 2006.

GABER MW, YUAN H, KILLMAR JT, NAIMARK MD, KIANI MF, MERCHANT TE: An intravital microscopy study of radiation-induced changes in permeability and leukocyte-endothelial cell interactions in the microvessels of the rat pia mater and cremaster muscle. Brain Res Brain Res Protoc 13: 1-10, 2004.

GAILlARD PJ, DE BOER AB, BREIMER DD: Pharmacological investigations on lipopolysaccharide-induced permeability changes in the blood-brain barrier in vitro. Microvasc Res 65: 24-31, 2003.

HANG CH, SHI JX, TIAN J, LI JS, WU W, YIN HX: Effect of systemic LPS injection on cortical NF-kappaB activity and inflammatory response following traumatic brain injury in rats. Brain Res 1026: 23-32, 2004.

HOFER S, BOPP C, HOERNER C, PLASCHKE K, FADEN RM, MARTIN E, BARDENHEUER HJ, WEIGAND MA: Injury of the blood brain barrier and up-regulation of icam-1 in polymicrobial sepsis. $J$ Surg Res 146: 276-281, 2008.

KABIR K, KELLER H, GRASS G, MINOR T, STUEBER F, SCHROEDER S, PUTENSEN C, PAUL C, BURGER C, RANGGER C, NEVILLE LF, MATHIAK G: Cytokines and chemokines in serum and urine as early predictors to identify septic patients on intensive care unit. Int J Mol Med 12: 565-570, 2003. 
KAYA M, PALANDUZ A, KALAYCI R, KEMIKLER G, SIMSEK G, BILGIC B, AHISHALI B, ARICAN N, KOCYILDIZ ZC, ELMAS I, KUCUK M, KARADENIZ A: Effects of lipopolysaccharide on the radiationinduced changes in the blood-brain barrier and the astrocytes. Brain Res 1019: 105-112, 2004.

LEHMANN C, BAC VH, PAVLOVIC D, LUSTIG M, MAIER S, FEYERHERD F, USICHENKO TI, MEISSNER K, HAASE H, JUNGER M, WENDT M, HEIDECKE CD, GRUNDLING M: Metronidazole improves intestinal microcirculation in septic rats independently of bacterial burden. Clin Hemorheol Microcirc 34: 427-438, 2006.

LEHMANN C, BIRNBAUM J, LUHRS C, RUCKBEIL O, SPIES C, ZIEMER S, GRUNDLING M, PAVLOVIC D, USICHENKO T, WENDT M, KOX WJ: Effects of C1 esterase inhibitor administration on intestinal functional capillary density, leukocyte adherence and mesenteric plasma extravasation during experimental endotoxemia. Intensive Care Med 30: 309-314, 2004.

LEHMANN C, FEYERHERD F, FEYERHERD T, FOGLIATA M, GRUNDLING M, USICHENKO TI, MEISSNER $\mathrm{K}$, WENDT M, PAVLOVIC D: Ketamine does not affect intestinal microcirculation in pentobarbitalanaesthetized rats during experimental endotoxaemia. Lab Anim 41: 55-62, 2007.

LEHMANN C, GEORGIEW A, WEBER M, BIRNBAUM J, KOX WJ: Reduction in intestinal leukocyte adherence in rat experimental endotoxemia by treatment with the 21-aminosteroid U-74389G. Intensive Care Med 27: 258263, 2001.

LEHMANN C, MEISSNER K, KNOCK A, DIEDRICH S, PAVLOVIC D, GRUNDLING M, USICHENKO T, WENDT M, BIRNBAUM J: Activated protein $\mathrm{C}$ improves intestinal microcirculation in experimental endotoxaemia in the rat. Crit Care 10: R157, 2006.

LUNDY DJ, TRZECIAK S: Microcirculatory dysfunction in sepsis. Crit Care Clin 25: 721-731, viii, 2009.

MAYHAN WG: Effect of lipopolysaccharide on the permeability and reactivity of the cerebral microcirculation: role of inducible nitric oxide synthase. Brain Res 792: 353-357, 1998.

OSUCHOWSKI MF, HE Q, SHARMA RP: Endotoxin exposure alters brain and liver effects of fumonisin B1 in BALB/c mice: implication of blood brain barrier. Food Chem Toxicol 43: 1389-1397, 2005.

PAUL R, KOEDEL U, WINKLER F, KIESEIER BC, FONTANA A, KOPF M, HARTUNG HP, PFISTER HW: Lack of IL-6 augments inflammatory response but decreases vascular permeability in bacterial meningitis. Brain 126: 1873-1882, 2003.

PYTEL P, ALEXANDER JJ: Pathogenesis of septic encephalopathy. Curr Opin Neurol 22: 283-287, 2009.

ROSENGARTEN B, WALBERER M, ALLENDOERFER J, MUELLER C, SCHWARZ N, BACHMANN G, GERRIETS T: LPS-induced endotoxic shock does not cause early brain edema formation - an MRI study in rats. Inflamm Res 57: 479-483, 2008.

RUSSELL J, COOPER D, TAILOR A, STOKES KY, GRANGER DN: Low venular shear rates promote leukocytedependent recruitment of adherent platelets. Am J Physiol Gastrointest Liver Physiol 284: G123-G129, 2003.

SIAMI S, ANNANE D, SHARSHAR T: The encephalopathy in sepsis. Crit Care Clin 24: 67-82, viii, 2008.

SINGH AK, JIANG Y: How does peripheral lipopolysaccharide induce gene expression in the brain of rats? Toxicology 201: 197-207, 2004.

SINGH AK, JIANG Y, GUPTA S, BENLHABIB E: Effects of chronic ethanol drinking on the blood brain barrier and ensuing neuronal toxicity in alcohol-preferring rats subjected to intraperitoneal LPS injection. Alcohol Alcohol 42: 385-399, 2007.

STRECK EL, COMIM CM, BARICHELLO T, QUEVEDO J: The septic brain. Neurochem Res 33: 2171-2177, 2008.

TSAO N, HSU HP, WU CM, LIU CC, LEI HY: Tumour necrosis factor-alpha causes an increase in blood-brain barrier permeability during sepsis. J Med Microbiol 50: 812-821, 2001.

VESZELKA S, PASZTOI M, FARKAS AE, KRIZBAI I, NGO TK, NIWA M, ABRAHAM CS, DELI MA: Pentosan polysulfate protects brain endothelial cells against bacterial lipopolysaccharide-induced damages. Neurochem Int 50: 219-228, 2007.

WANG $\mathrm{H}, \mathrm{MA} \mathrm{S}$ : The cytokine storm and factors determining the sequence and severity of organ dysfunction in multiple organ dysfunction syndrome. Am J Emerg Med 26: 711-715, 2008.

XAIO H, BANKS WA, NIEHOFF ML, MORLEY JE: Effect of LPS on the permeability of the blood-brain barrier to insulin. Brain Res 896: 36-42, 2001. 